\section{Evidence for state-dependent learning with mescaline in a passive avoidance task ${ }^{*}$}

\author{
RONALD K. SIEGEL and MURRAY E. JARVIK \\ Albert Einstein College of Medicine, Bronx, N.Y. 10461
}

Mice performed a passive avoidance task poorly when trained under mescaline or water and tested $24 \mathrm{~h}$ later under the opposite drug conditions. Ss showed good performance of the learned response and high retest latencies when trained and tested under identical drug conditions. These effects were observed with a $1-h$ pretreatment time (excitatory phase) but not with a $30-\mathrm{min}$ pretreatment (inhibitory phase) or with immediate posttrial treatment. Nonshocked control animals receiving identical drug treatments showed no differences in retest latencies. Results are discussed in terms of state-dependent learning.

Several studies have shown that the performance of behaviors learned while an animal is drugged (D) may sometimes appear conditional upon the drug state present during learning. Furthermore, the learned response may fail to transfer or only partially transfer into other drug or nondrugged (ND) states (cf. Overton, 1969). Such state-dependent or dissociated learning has been extensively investigated with many centrally acting drugs, although the hallucinogens have been relatively ignored. In man, there are abundant clinical reports suggesting that hallucinogens like nitrous oxide (Greenberg, Mahler, \& Pearlman, 1969; Steinberg, 1956) and psilocybin (Fischer, 1971) produce dramatic dissociated effects. The strong correlation between such drug-induced hallucinations in man and drug-induced head twitches in mice invites further animal experimentation. In addition, there is some evidence that mescaline itself may produce moderate dissociation in rodents (Overton, 1968). Thus, the present series of experiments were designed to assess the effects of mescaline in a state-dependent paradigm with mice.

\section{GENERAL METHOD}

The Ss were 1,200 naive female mice (CF 1 and Simonsen), 8-10 weeks old (20-25 g). They were housed 20 per cage with free access to food and water. All experimental procedures were conducted during the daylight phase of a 12-h day-night cycle.

The step-through passive avoidance apparatus used has been described in detail elsewhere (Jarvik \& Kopp, 1967). Briefly, the apparatus consisted of a two-compartment box in which the animal could receive a $320-\mathrm{mA}$

*Supported by Grants MH-05319 and MH-6418 from NIMH. We thank Scott Beadenk opf for technical assistance. Reprints are available from Ronald $K$. Siegel, Department of Pharmacology, University of California at Los Angeles, LoS Angeles, Calif. 90024. footshock (FS) for stepping from a small lighted compartment to a larger darkened one. Ss escaping from the FS to the lighted compartment were removed. The same procedure was employed for retest trials, which were run 24 h later without FS.

Ss were randomly assigned to one of four experimental groups employed in a 2 by 2 factorial design. Each $S$ was trained with one drug condition and then tested with the same or another drug condition. The two conditions were mescaline hydrochloride (100 $\mathrm{mg} / \mathrm{kg}, \mathrm{IP}$ ) in a water vehicle (D) with a constant volume of $20 \mathrm{ml} / \mathrm{kg}$ or vehicle alone (ND). The dose of mescaline was independently determined to be an effective dose for eliciting head twitches and yet has been found to have no blocking effect on conditioned and unconditioned responses in rats (Cook \& Weidley, 1957). The four experimental groups and treatment conditions followed the general state-dependent design of ND-ND, ND-D, D-ND, and D-D.

\section{EXPERIMENT 1}

The purpose of Experiment 1 was to determine the effects of mescaline and water when administered $1 \mathrm{~h}$ prior to training and $1 \mathrm{~h}$ prior to retesting. This pretreatment time corresponds to the excitatory phase of mescaline on shuttle avoidance in rats (Smythies \& Sykes, 1964). The Ss were divided into the following groups and treatments: all Ss in groups designated A and B (replication) received FS on the training day, while those in groups designated $C$ did not receive $F S$. Groups 1A $(\mathrm{N}=20), 1 \mathrm{~B}(\mathrm{~N}=40)$, and $1 \mathrm{C}(\mathrm{N}=40)$ all received water both times (water-water); Groups 2A $(\mathrm{N}=20), \quad 2 \mathrm{~B} \quad(\mathrm{~N}=40), \quad$ and $2 \mathrm{C}$ $(N=40)$ received water-mescaline; Groups $3 A(N=20), 3 B(N=40)$, and $3 \mathrm{C}(\mathrm{N}=40)$ received mescaline-water; and Groups $4 \mathrm{~A}(\mathrm{~N}=20), 4 \mathrm{~B}(\mathrm{~N}=40)$, and $4 \mathrm{C} \quad(\mathrm{N}=40)$ received mescaline-mescaline. Results

The results of Experiment 1 are presented in Table 1 in terms of the median retest latencies in seconds for Ss to step through from the front compartment to the dark compartment. An arbitrary cutoff of $600 \mathrm{sec}$ was used in these retests. Animals in Group 3A showed significantly lower latencies than those in Group 1A $(\mathrm{p}=.001$; Wilcoxon, Katti, \& Wilcox, 1963), as did those in Group 3B when compared with Group 1B $(p=.01)$. Indeed, latencies for Group 3B were significantly lower than those in Groups $2 B(p=.01)$ and $4 \mathrm{~B}(\mathrm{p}=.01)$, but these were in turn still faster than Group 1B. No significant differences were observed between the nonshocked $\mathrm{C}$ groups.

\section{EXPERIMENT 2}

This experiment examined the effects of mescaline and water when administered $30 \mathrm{~min}$ prior to training and $30 \mathrm{~min}$ prior to retesting. This pretreatment time corresponds to the peak inhibitory action of mescaline on avoidance behavior (Smythies \& Sykes, 1964). Ss were divided into the same sized groups and treatment conditions as in Experiment 1, with the addition that animals in groups designated $D$ received an additional dose of mescaline $(100 \mathrm{mg} / \mathrm{kg}, \quad \mathrm{P})$ $24 \mathrm{~h}$ prior to training.

$$
\text { Results }
$$

The results of Experiment 2 are presented in Table 2 in terms of the median retest latencies. Here, all $\mathrm{Ss}$ in Groups 2, 3, and 4 showed significantly faster latencies than those in Groups 1 which reached the cutoff median of $600 \mathrm{sec}$. There were no significant differences between nonshocked groups.

\section{EXPERIMENT 3}

This experiment was designed to assess drug effects when administered immediately following training and $1 \mathrm{~h}$ prior to restesting. Ss were divided into identically sized groups and treatments as in Experiment 1.

$$
\text { Results }
$$

The results of Experiment 3 are presented in Table 3 in terms of median retest latencies for all groups. Animals in Groups $4 \mathrm{~A}$ and $4 \mathrm{~B}$ showed significantly faster latencies than those in Groups $1 \mathrm{~A} \quad(\mathrm{p}=.01)$ and $1 \mathrm{~B}$ $(p=.01)$ and those in Groups $2 A$

Table 1

Median Retest Latencies (in Seconds) for All Groups in Experiment 1*

\begin{tabular}{crrrr}
\hline & \multicolumn{5}{c}{ Group } \\
\cline { 2 - 5 } group & \multicolumn{1}{c}{1} & \multicolumn{1}{c}{2} & 3 & 4 \\
\hline A & 367.7 & 454.4 & 90.8 & 179.4 \\
B & $>600.0$ & 163.8 & 25.1 & 175.3 \\
C & 11.9 & 14.9 & 13.3 & 12.6 \\
\hline
\end{tabular}

*Groups: 1, ND-ND; 2, ND-D; 3, D-ND, $4, D-D$. Subgroups $A$ and $B$ received foot. shock during training, while Subgroup $C$ did not. 
Table 2

Median Retest Latencies (in Seconds) for All Groups in Experiment 2*

\begin{tabular}{cccrr}
\hline Subgroup & Group 1 & Group 2 & Group 3 & Group 4 \\
\hline A & $>600.0$ & 42.0 & 59.6 & 64.5 \\
B & $>600.0$ & 118.1 & 253.7 & 115.4 \\
C & 11.6 & 11.8 & 14.1 & 10.2 \\
D & $>600.0$ & 60.9 & 63.2 & 83.6
\end{tabular}

*Groups: $1, N D \cdot N D: 2, N D \cdot D ; 3, D \cdot N D ; 4, D \cdot D$. Subgroups $A$ and $B$ received footshock during training, while Subgroup $C$ did not. Subgroup $D$ received an additional treatment with mescaline $24 \mathrm{~h}$ prior to training.

$(\mathrm{p}=.05)$ and $2 \mathrm{~B}(\mathrm{p}=.02)$. In addition, Group 2A latencies were significantly lower than those of Group $1 \mathrm{~A}$ $(\mathrm{p}=.01)$, while no differences were observed between nonshocked groups. DISCUSSION

The results of Experiment 1 indicate that the learned response was performed poorly in the D-ND (Groups 3A and 3B) and ND-D (Group 2B) conditions after the change in drug conditions. Concomitantly, a nimals showed continued good performance and high latencies in ND-ND (Groups 1A and 1B) and D-D (Groups 4A and 4B) conditions. This pattern of results is the usual criterion for distinguishing drug effects from state change effects (cf. Overton, 1968) and is suggestive here of state-dependent learning with mescaline. However, the high latencies observed for Group 2A cautions us not to accept this interpretation too readily. These effects were not observed in Experiment 2, which employed a 30-min pretreatment interval as all animals receiving mescaline ran faster than the ND-ND group (Table 2) and were thus impaired in either acquisition or performance of the passive avoidance task. Since this pretreatment time has previously been reported to produce behavioral inhibition of active avoidance, the results seem to support Overton's (1968) hypothesis that state-dependent learning is not observed in passive avoidance tasks where acquisition is severely impaired (e.g., Bohdanecky \& Jarvik, 1967). While alternative explanations based on altered drive levels, drug-shock interactions, drug withdrawal, or cumulative drug action cannot be ruled out, an additional mescaline treatment in Group 1D (Table 2) did not impair performance which would seem to control for some of these objections like the latter. Furthermore, the treatment effects seem at least contingent on the learned responses, as no significant differences were observed in the retest latencies of nonshocked animals (Experiments 1 and 2). Thus, the present results are different from recent experiments suggesting that mescaline facilitates performance rather than acquisition of shuttle avoidance in rats (Mandel \& Bridger, in press).

When mescaline was administered immediately following training in Experiment 3, no retroactive effects were observed in D-ND retest performance (Table 3 ). When tested under mescaline, animals in Groups 2A and $2 \mathrm{~B}$ showed low latencies similar to those seen in Experiment 1 (Group 1B). This particular result stands in contrast to other findings suggesting that asymmetrical dissociation favors transfer from ND to D states (e.g., Barnhart \& Abbott, 1967). Furthermore, $S s$ in the D-D condition (Groups 4A and 4B, Table 3) showed the poorest performance and lowest retest latencies of all groups. Since D-D animals in Experiment 1 did not

Table 3

Median Retest Latencies (in Seconds) for All Groups in Experiment 3*

\begin{tabular}{ccccc}
\hline Subgroup & Group 1 & Group 2 & Group 3 & Group 4 \\
\cline { 2 - 5 } A & 313.0 & 180.2 & 290.0 & 98.6 \\
B & 365.6 & 189.9 & $>600.0$ & 92.5 \\
C & 12.6 & 6.3 & 7.7 & 14.0 \\
\hline
\end{tabular}

*Groups: $1, N D \cdot N D ; 2, N D \cdot D ; 3, D \cdot N D: 4 . D \cdot D$. Subgroups $A$ and $B$ received footshock during training, while Subgroup $C$ did not. manifest such impaired performance, it may be speculated that these results reflect a dissociated amnesia induced by posttrial mescaline administration. While these effects and their underlying mechanisms of action need to be examined more exhaustively, they do appear similar to the recently reported dissociation of ECS-induced amnesia in mice (Thompason \& Neely, 1970; Gardner, Glick, \& Jarvik ${ }^{1}$ ).

\section{REFERENCES}

BARNHART, S. S., \& ABBOTT, D. W. Dissociation of learning and meprobamate. Psychological Reports, $1967,20,520-522$.

BOHDANECKY, Z., \& JARVIK, M. E. The effect of D-amphetamine and physostigmine upon acquisition and retrieval in a single trial learning task. Archives of Internationa Pharmacodynamics, 1967, 170, 58-65.

COOK, L., \& WEIDLEY, E. Behavioral effects of some psychopharmacological agents. Annals of the New York Academy of Sciences, 1957, 66, 740-752.

F ISCHER, R. The 'flashback': Arousal-statebound recall of experience. Journal of Psychedelic Drugs, 1971, 3 31-39.

GREENBERG， R. , MAHLER， D. \& PEARLMAN, C. Dreaming and nitrous oxide. Archives of General Psychiatry. 1969, 21, 691-695.

JARVIK, M. E., \& KOPP, R. An improved one-trial passive avoidance learning situation. Psychological Reports. 1967. 21, 221-224.

MANDEL, I. J \& \& BRIDGER, W. $H$. Mescaline facilitates performance of shuttle avoidance by rats during acquisition. Biological Psychiatry, in press.

OVERTON, D Dissociated leaming in drug states (state dependent learning). In $\mathrm{D}$. $\mathrm{H}$. Effron (Ed.), Psychopharmacology, $A$ Review of Progress 1957-1967. Washington, D.C: Public Health Service Publication No. 1836, 1968, Pp. 918-930.

OVERTON,D. A. Discriminative control of behavior by drug states. Paper presented for the Symposium on Stimulus Properties of Drugs, University of Minnesota, Minneapolis, Minn., 1969.

SMYTHIES, J. R., \& SYKES, E. A. The effect of mescaline upon the conditioned avoidance response in the rat. Psychopharmacologia (Berlin), 1964, 6. 163-172.

STEINBERG, H. 'Abnormal behavior' induced by nitrous oxide. British Joumal of Psychology, 1956, 47, 183-194.

THOMPSON, C. I., \& NEELY, J. E. Dissociated learning in rats produced by electroconvulsive shock. Physiology \& Behavior, 1970, $5,783-786$.

WILCOXON, F., KATTI, S. K \& WILCOX, R. A. Critical values and probability levels for the Wilcoxon Rank Sum Test and the Wilcoxon Ran Test. Lederle Laboratories Division, American Cyanamid Company, 1963.

\section{NOTE}

1. Gardner, E. L., Glick, S. D., \& Jarvik M. E. ECS dissociation of learning and one-way cross-dissociation with physostigmine and scopolamine. In preparation. 